\title{
An Unusual Alkylidyne Homologation
}

\author{
Yong-Shen Han, Anthony F. Hill* and Richard Y. Kong
}

$\mathrm{R} /$

The reaction of $\left[\mathrm{W}(\equiv \mathrm{CH}) \operatorname{Br}(\mathrm{CO})_{2}(\mathrm{dcpe})\right]$ (dcpe = 1,2bis(dicyclohexylphosphino)ethane) with ${ }^{\mathrm{t}} \mathrm{BuLi}$ and $\mathrm{SiCl}_{4}$ affords the trichlorosilyl ligated neopentylidyne complex $\left[\mathrm{W}\left(\equiv \mathrm{C}^{t} \mathrm{Bu}\right)\left(\mathrm{SiCl}_{3}\right)(\mathrm{CO})_{2}(\mathrm{dcpe})\right]$. This slowly reacts with $\mathrm{H}_{2} \mathrm{O}$ to afford $\left[\mathrm{W}\left(\equiv \mathrm{CCH}_{2}{ }^{t} \mathrm{Bu}\right) \mathrm{Cl}_{3}\right.$ (dcpe)] and ultimately $\mathrm{H}_{2} \mathrm{C}=\mathrm{CH}^{t} \mathrm{Bu}$ via an unprecented alkylidyne homologation in which coordinated $\mathrm{CO}$ is the source of the additional carbon atom with potential relevance to the Fischer-Tropsch process.

The Fischer-Tropsch process (Equation 1 ) by which syn gas (CO, $\mathrm{H}_{2}$ ) is converted to a mixture of hydrocarbons is of enduring interest as industry looks to replace petrochemical resources with renewable biomass. ${ }^{1}$

$$
\mathrm{CO}+\mathrm{H}_{2} \rightarrow \mathrm{C}_{x} \mathrm{H}_{y} \mathrm{O}_{z}+\mathrm{H}_{2} \mathrm{O}
$$

Being a heterogeneously catalysed process, attention has turned to molecular entities that might mimic the obscure chemical events that occur on catalyst surfaces. ${ }^{2}$ This has uncovered a cornucopia of possible mechanistic candidates to account for the two key steps (i) $\mathrm{CO}$ reduction $(\mathrm{C}-\mathrm{H}$ bond formation) and (ii) carbon chain growth ( $\mathrm{C}-\mathrm{C}$ bond formation).

Carbynes ' $C R$ ' ( $\mathrm{R}=\mathrm{OH}, \mathrm{H}$, hydrocarbyl) are amongst the many ' $C_{1}$ ' entities suspected of playing a surreptitious role on heterogeneous surfaces ${ }^{3}$ and their coupling reactions with other $\mathrm{C}_{1}$ ligands are therefore of interest. Amongst these, the coupling of carbyne and carbonyl ligands to provide ketenyls 4,5 is the most studied, however recently Buss and Agapie have demonstrated the remarkable reductive deoxygenation $\left(\mathrm{KC}_{8} / \mathrm{ClSiMe}_{3}\right)$ of a carbonyl ligand in $\left[\mathrm{W}(\mathrm{CO})_{2}\left\{\mathrm{C}_{6} \mathrm{H}_{4}\left(\mathrm{C}_{6} \mathrm{H}_{4} \mathrm{P}^{i} \mathrm{Pr}_{2}\right)_{2}\right]\right.$ to ultimately afford the silylcarbyne complex $\left[\mathrm{W}(\equiv \mathrm{CSiMe})_{3} \mathrm{Cl}(\mathrm{CO})\left\{\mathrm{C}_{6} \mathrm{H}_{4}\left(\mathrm{C}_{6} \mathrm{H}_{4} \mathrm{P}^{i} \mathrm{Pr}_{2}\right)_{2}\right]{ }^{6}\right.$ We report herein an intriguing transformation in which both $\mathrm{CO}$ reduction and chain homologation are observed on a molecular single-site metal complex.

Treating the methylidyne complex $\left[\mathrm{W}(\equiv \mathrm{CH}) \mathrm{Br}(\mathrm{CO})_{2}(\mathrm{dcpe})\right](\mathbf{1})^{7}$ with ${ }^{\mathrm{B}} \mathrm{BuLi}$ followed by a range of electrophilic reagents leads via $\mathrm{Li}\left[\mathrm{W}\left(\equiv \mathrm{C}^{t} \mathrm{Bu}\right)(\mathrm{CO})_{2}(\mathrm{dcpe})\right]$ to the neopentylidyne complexes $\left[\mathrm{W}\left(\equiv \mathrm{C}^{t} \mathrm{Bu}\right)(\mathrm{E})(\mathrm{CO})_{2}\right.$ (dcpe)] (E = SnMe $\mathrm{S}_{3} \mathbf{2 a}, \mathrm{SPh} \mathbf{2 b}, \mathrm{SePh} \mathbf{2 c}, \mathrm{TePh} \mathbf{2 d}, \mathrm{Cl}$ $\mathbf{2 e}, \mathrm{Br} \mathbf{2 f}) .{ }^{8}$ Attempts to prepare the silicon analogue of $\mathbf{2 a}$ with

\footnotetext{
a. Research School of Chemistry, Australian National University, Canberra, Australian Capital Territory, Australia ACT 2601.Email. a.hill@anu.edu.au

+ CCDC 1557985, 1557986, 1557899 and 1587450 contain the supplementary crystallographic data for this paper, and are available free of charge from The Cambridge Crystallographic Data Centre. See DOI: 10.1039/x0xx00000x
}

$\mathrm{ClSiMe}_{3}$ were unsuccessful (see ESI), however employing $\mathrm{SiCl}_{4}$ as the electrophilic quench resulted in the isolation of the carbyne complex $\left[\mathrm{W}\left(\equiv \mathrm{C}^{t} \mathrm{Bu}\right)\left(\mathrm{SiCl}_{3}\right)(\mathrm{CO})_{2}(\mathrm{dcpe})\right](3$, Scheme 1$)$, akin to the various derivatives $\mathbf{2}$, but notable in some respects.<smiles>O=[N+]([O-])[N+]([O-])([O-])[O-]</smiles>

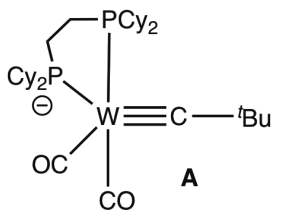

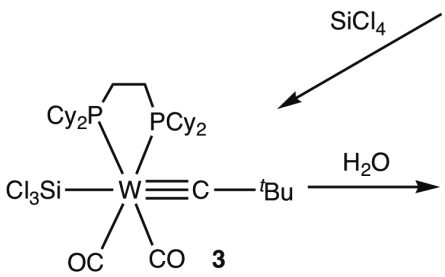

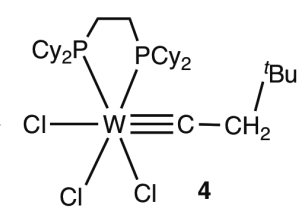

Scheme 1. Synthesis and hydrolysis of a silyl carbyne complex.

A small number of tungsten trichlorosilyl complexes are known ${ }^{9}$ though none have been structurally characterised and all are described as unstable. Accordingly, the complete characterisation of $\mathbf{4}$ included a crystallographic analysis, summarised in Figure 1.

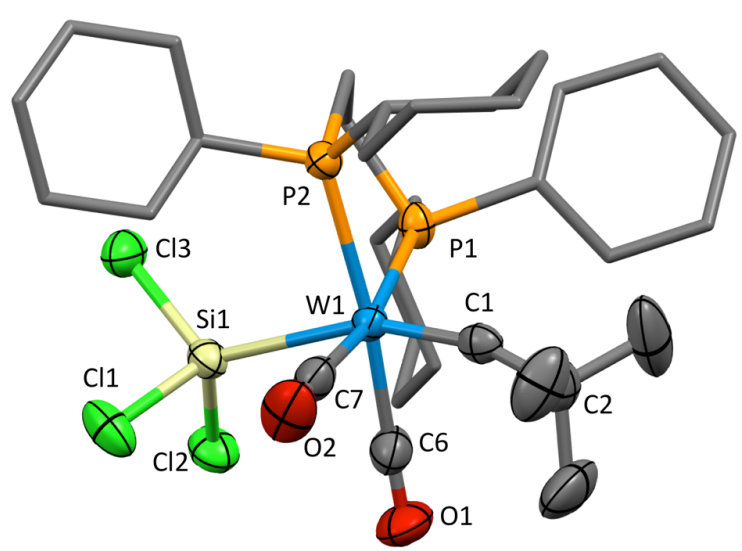

Figure 1. Molecular structure of $\mathbf{3}$ in a crystal (60\% displacement ellipsoids, $\mathrm{H}$ atoms omitted, cyclohexyl groups simplified, one of two crystallographically independent molecules shown). Selected bond lengths ( $\AA$ ) and angles: W1-Si1 2.6880(9), W1-P1 2.5473(8), W1-P2 2.5590(8), W1-C1 1.834(3), W1-C1-C2 164.1(3), C1-W1-Si1 159.50(10), P1-W1-P2 78.79(3).

The structural features associated with the ' $\mathrm{W}\left(\mathrm{C}^{t} \mathrm{Bu}\right)(\mathrm{CO})_{2}(\mathrm{dcpe})^{\prime}$ moiety generally conform to patterns 
established for complexes $2 .{ }^{7}$ The $\mathrm{SiCl}_{3}$ ligand provides the focus of interest and immediately it is apparent that the W1-Si1 bond is particularly elongated relative to those seen in other structurally characterised tungsten silyl complexes. ${ }^{9}$ Because trichlorosilyl ligands typically show far shorter metal-silicon bond lengths than corresponding triorganosilyls (e.g., $\left[\mathrm{Mn}\left(\mathrm{SiR}_{3}\right)(\mathrm{CO})_{5}\right] \mathrm{R}=\mathrm{Cl}$, 10a $\mathrm{Ph}^{10 \mathrm{~b}}$ and $\left[\mathrm{Fe}\left(\mathrm{SiR}_{3}\right)_{2}(\mathrm{CO})_{4}\right] \mathrm{R}=\mathrm{Cl}, 10 \mathrm{c}$ $\mathrm{Me}^{10 \mathrm{~d}}$ ) we may attribute this to the characteristically superlative trans influence of carbyne ligands. ${ }^{11}$ Long W-Si $(2.753 \AA)$ and short W-C (1.823 $\AA$ ) bond lengths were also observed when the geometry of the model complex $\mathrm{W}(\equiv \mathrm{CH})\left(\mathrm{SiCl}_{3}\right)(\mathrm{CO})_{2}$ (dmpe) was optimised at the B3LYP-LANL2DZ level (see ESI).

The chemical implications of this weak tungsten-silicon bond soon became apparent when it was observed that 3 reacted with even traces of adventitious moisture. Over a period of two $\left(\mathrm{CDCl}_{3}\right)$ or four $\left(\mathrm{C}_{6} \mathrm{D}_{6}\right)$ days, signals for $\mathbf{3}$ were entirely replaced by those for a new complex formulated as the neohexylidyne $\left[\mathrm{W}\left(\equiv \mathrm{CCH}_{2}{ }^{t} \mathrm{Bu}\right) \mathrm{Cl}_{3}(\mathrm{dcpe})\right]$ (4) on the basis of spectroscopic and crystallographic (Figure 2) data. During this time, an intermediate $\mathbf{5}$ was seen to accumulate and then slowly evolve to $\mathbf{4}$ (vide infra). Unfortunately, the rates of formation of $\mathbf{5}$, its conversion to $\mathbf{4}$ and the contemporaneous onset of hydrolysis of 4 to $\left[\mathrm{W}(=\mathrm{O}) \mathrm{Cl}_{3}(\mathrm{dcpe})\right] \quad(6$, structurally characterised, see $\mathrm{ESI}$ ) and $\mathrm{H}_{2} \mathrm{C}=\mathrm{CH}^{t} \mathrm{Bu}$ precluded $\mathbf{4}$ or $\mathbf{5}$ being exclusively isolated in pure form. Full solution spectroscopic data could, however be extracted for $\mathbf{4}$ and $\mathbf{5}$ by monitoring the time-course of the reactions by 1 and $2-\mathrm{D}{ }^{1} \mathrm{H},{ }^{13} \mathrm{C}$ and ${ }^{31} \mathrm{P} N M R$ spectroscopies and the identity of $\mathbf{4}$ was further confirmed crystallographically (Figure 2). Trihalo carbyne complexes of tungsten are well-known, ${ }^{12-15}$ and related molybdenum complexes have gained prominence as

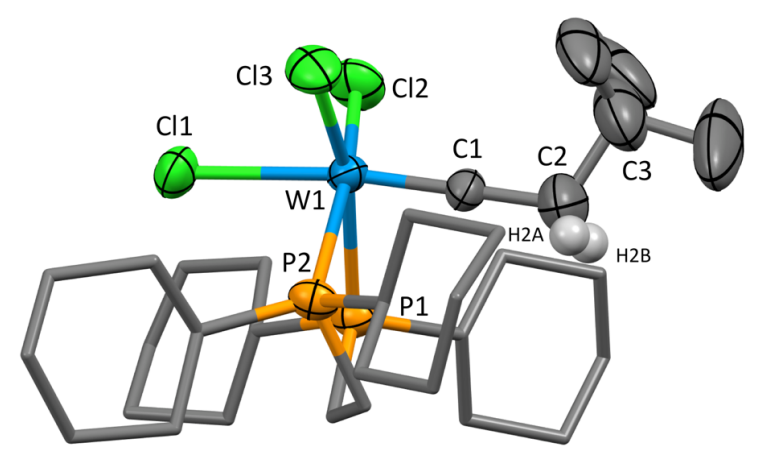

Figure 2. Molecular structure of 4 in a crystal ( $50 \%$ displacement ellipsoids, $\mathrm{H}$ atoms omitted, cyclohexyl groups simplified, extensive disorder for cyclohexyl groups not shown). Selected bond lengths (Å) and angles: W1-P1 2.5587(17), W1-P2 2.5634(16), W1-Cl1 2.5737(18), W1-Cl2 2.3363(18), W1-Cl3 2.3421(18), W1-C1 1.783(6), C1-C2 1.479(11), P1-W1-P2 77.83(5), Cl2-W1-Cl3 103.90(8), C2-C1-W1 179.6(7).

intermediates en route to 'user friendly' alkyne metathesis mediators. ${ }^{16}$

The geometry about tungsten in $\mathbf{4}$ is distorted octahedral, displaying the especially strong trans influence of the essentially linear $\left(\mathrm{W}-\mathrm{C} 1-\mathrm{C} 2=179.6(7)^{\circ}\right)$ neohexylidyne ligand, such that the $\mathrm{W}-\mathrm{Cl}$ bond trans to the carbyne $(\mathrm{W} 1-\mathrm{Cl} 1=2.5737(18) \AA)$ is significantly elongated (130 e.s.d.) relative to those trans to the phosphine donors (2.3363(18), 2.3421(18)Å). Notable spectroscopic data for 4 include a carbyne resonance $\left(\delta_{c}=\right.$
288.0) with ${ }^{2} J_{\mathrm{PC}}(7.8 \mathrm{~Hz})$ not dissimilar to that observed for $\left[\mathrm{W}\left(\equiv \mathrm{C}^{\mathrm{t}} \mathrm{Bu}\right) \mathrm{Cl}(\mathrm{CO})_{2}(\mathrm{dcpe})\right]\left(2 \mathrm{e}: \delta_{\mathrm{C}}=289.5,{ }^{2} \mathrm{~J}_{\mathrm{CP}}=7.6 \mathrm{~Hz}\right),{ }^{8}$ i.e., oxidation of the metal from $\mathrm{d}^{2}$ to $\mathrm{d}^{0 \dagger}$ does not significantly impact the coupling, which appears primarily dictated by coordination number. Secondly, the singlet resonance observed at $\delta_{\mathrm{P}}=54.7$ in the ${ }^{31} \mathrm{P}\left\{{ }^{1} \mathrm{H}\right\} \mathrm{NMR}$ spectrum has ${ }^{1} J_{\mathrm{PW}}=220 \mathrm{~Hz}$ which is again comparable to that found for $2 \mathrm{e}\left(\delta_{\mathrm{P}}=46.01,{ }^{1} \mathrm{JWW}_{\mathrm{PW}}=224\right.$ $\mathrm{Hz}$ ). Thus, it is useful to note here that whilst the chemical shift is responsive to changes in the oxidation state of tungsten in these two octahedral complexes, the magnitude of ${ }^{183} \mathrm{~W}-31 \mathrm{P}$ coupling is not (vide infra).

Though not isolated, a neohexylidene complex $\left[\mathrm{W}\left(=\mathrm{CHCH}_{2}{ }^{t} \mathrm{Bu}\right)(=\mathrm{O}) \mathrm{Cl}_{2}(\mathrm{dcpe})\right] \quad(7), \quad$ akin to $\left[\mathrm{W}\left(=\mathrm{CH}^{t} \mathrm{Bu}\right)(=\mathrm{O}) \mathrm{Cl}_{2}\left(\mathrm{PMe}_{3}\right)_{2}\right], 17,18$ would seem a plausible intermediate en route from 4 to $\mathbf{6}$. Whilst ample literature precedent exists for the latter stages of the hydrolytic decomposition of $\mathbf{4}$, the homologation of a carbyne ligand (neopentylidyne to neohexylidyne) is unprecedented and the analogues of $\mathbf{3}$, i.e., complexes $\mathbf{2}$ are indefinitely stable, thus implicating the $\mathrm{SiCl}_{3}$ ligand in this transformation. The conversion of $\mathbf{3}$ to $\mathbf{4}$ is not noticeably accelerated by addition of anhydrous $\mathrm{HCl}$ and we therefore presume that adventitious moisture is crucial to the conversion. Furthermore, the chlorocomplex $2 \mathrm{e}$ does not react with trichlorosilane to afford a neopentylidene (See ESI). The new carbyne carbon in $\mathbf{4}$ must originate from a carbonyl co-ligand and three possible coupling processes might be considered. Specifically, carbonyl ligands have been shown to couple with alkylidyne, alkylidene or alkyl ligands to afford ketenyl, ${ }^{5}$ ketene $\mathrm{e}^{19}$ or acy| ${ }^{20}$ ligands.

In each case the coupling increases the nucleophilicity of the oxygen towards 'hard' electrophiles, a corollary being that such processes may be Lewis acid mediated. ${ }^{21}$ It would therefore appear that the $\mathrm{SiCl}_{3}$ ligand serves a dual role in providing not only the requisite $\mathrm{HCl}$ via hydrolysis, but also acts as a reductive oxide abstractor (as spectroscopically clandestine ' $\mathrm{SiO}_{2}$ '). As to the order of events, we eschew mechanistic pathways involving direct and most likely irreversible $\mathrm{W}-\mathrm{O}$ bond formation. Noting, however, the unusually long W-Si bond observed in $\mathbf{3}$, we have considered a mechanism (Scheme 2) in which nucleophilic attack $\left(\mathrm{H}_{2} \mathrm{O}\right.$ or $\left.\mathrm{HO}^{-}\right)$at this ligand instigates heterolytic dissociation (effectively $S_{\mathrm{N}} 2$ at silicon), only to have the resulting $\mathrm{Cl}_{3} \mathrm{SiOH}$ immediately re-coordinate to an oxygen atom of a carbonyl ligand of A, prior to CO-CR coupling. Such a process would appear more plausible than a direct and geometrically unfavourable intramolecular 1,3-migration of the $\mathrm{SiCl}_{3}$ group along a linear WCO spine.

Silylation of electron rich carbonyl ligands has been demonstrated by Lippard ${ }^{22}$ and Peters ${ }^{3}$ for sufficiently sterically occluded metal centres and we find the spectroscopic data for the intermediate 5 to be consistent with a siloxycarbyne ${ }^{3,22}$ rather than a siloxyalkyne ${ }^{21,23}$ or ketenyl ${ }^{4,5}$ complex. Specifically, the molecule has no element of

symmetry and three low field resonances are observed at $\delta_{\mathrm{C}}=$ $320.4\left(\mathrm{dd}, 2 \mathrm{~J}_{\mathrm{PC}}=8,20\right.$; strong $\mathrm{HMBC}$ with $\left.\delta_{\mathrm{H}}\left(\mathrm{CH}_{3}\right)=1.23\right), 213.9$ $\left(t,{ }^{2} J_{\mathrm{PC}}=16,{ }^{1} J_{\mathrm{WC}}=127\right)$ and $213.3\left(\mathrm{dd},{ }^{2} J_{\mathrm{PC}}=8,22 \mathrm{~Hz}\right)$, the former being typical of an alkylidyne whilst the latter two are consistent with terminal carbonyl and siloxy carbyne carbon nuclei, with no significant $\mathrm{HMB}$ correlation with $\delta_{\mathrm{H}}\left(\mathrm{CH}_{3}\right)$ resonances. The 
${ }^{31} \mathrm{P}\left\{{ }^{1} \mathrm{H}\right\}$ NMR spectrum comprises an $\mathbf{A X}$ system $\left(\delta_{\mathrm{P}}=26.3,45.3\right.$, $2 J_{A B}=4.4 \mathrm{~Hz}$ ) the resonances for which show disparate couplings to tungsten $(226,76 \mathrm{~Hz}$ ) reflecting the varying s-character of axial and equatorial bonding in the proposed trigonal bipyramidal geometry of $\left[\mathrm{W}\left(\equiv \mathrm{C}^{t} \mathrm{Bu}\right)\left(\equiv \mathrm{COSiCl}_{2} \mathrm{X}\right)(\mathrm{CO})(\mathrm{dcpe})\right](\mathbf{5}$; Scheme 2). By the time the proportion of $\mathbf{5}$ reaches a maximum $(t=4 \mathrm{hrs}$ ), the spectrum already indicates up to $28 \%$ onconversion to 4 . The postulate of an intermediate bis(carbyne) complex is contentious but not without limited precedent, e.g., the aminomethylidyne salts trans- $\left[\mathrm{W}(\mathrm{CNHMe})_{2}(\mathrm{dppe})_{2}\right]\left(\mathrm{BF}_{4}\right)_{2}{ }^{24 a}$ and $\left[\mathrm{W}\left(\mathrm{CNEt}_{2}\right)_{2}(\mathrm{CNEt})\left(\eta-\mathrm{C}_{5} \mathrm{Me}_{5}\right)\right]\left(\mathrm{BF}_{4}\right){ }^{24 \mathrm{~b}}$ The former is precluded from carbyne-carbyne coupling by the trans geometry, whilst the latter undergoes such coupling when treated with EtNC or $\mathrm{Br}_{2}$. Computational studies suggest that carbyne-carbyne coupling is symmetry forbidden for $d^{6}$ metal centres and allowed but energetically unfavourable for $\mathrm{d}^{4}$ centres (neutral CR formalism). ${ }^{25}$ We therefore attribute the longevity of $\mathrm{d}^{6-5}$ to this forbidden process that becomes favourable when oxidised by adventitious $\mathrm{HCl}$ arising from $\mathrm{Si}-\mathrm{Cl}$ hydrolysis.

To conclude, we have presented a contribution to the already complex array of models of Fischer-Tropsch processes, specifically one that combines both carbon chain homologation and $\mathrm{CO}$ reduction.

$$
\begin{gathered}
\mathrm{L}_{n} \mathrm{M}(\mathrm{CO})(\equiv \mathrm{CR})\left(\mathrm{SiCl}_{3}\right)+\mathrm{H}_{2} \mathrm{O} \rightarrow \mathrm{L}_{n} \mathrm{MCl}_{3}\left(\equiv \mathrm{CCH}_{2} \mathrm{R}\right)+\mathrm{SiO}_{2} \downarrow \\
\mathrm{L}_{\mathrm{n}} \mathrm{MCl}_{3}\left(\equiv \mathrm{CCH}_{2} \mathrm{R}\right)+\mathrm{H}_{2} \mathrm{O} \rightarrow \mathrm{L}_{n} \mathrm{M}(=\mathrm{O}) \mathrm{Cl}_{3}+\mathrm{H}_{2} \mathrm{C}=\mathrm{CHR}
\end{gathered}
$$

In the present case, the driving force for this carbon chain homologation is the exothermicity of ' $\mathrm{SiO}_{2}$ ' formation, whilst alkene formation is thermodynamically compensated for by $\mathrm{W}=\mathrm{O}$ bond installation. In a Fischer-Tropsch context these would correspond to metal oxide formation, the oxide being reactivated by reduction with hydrogen/CO.

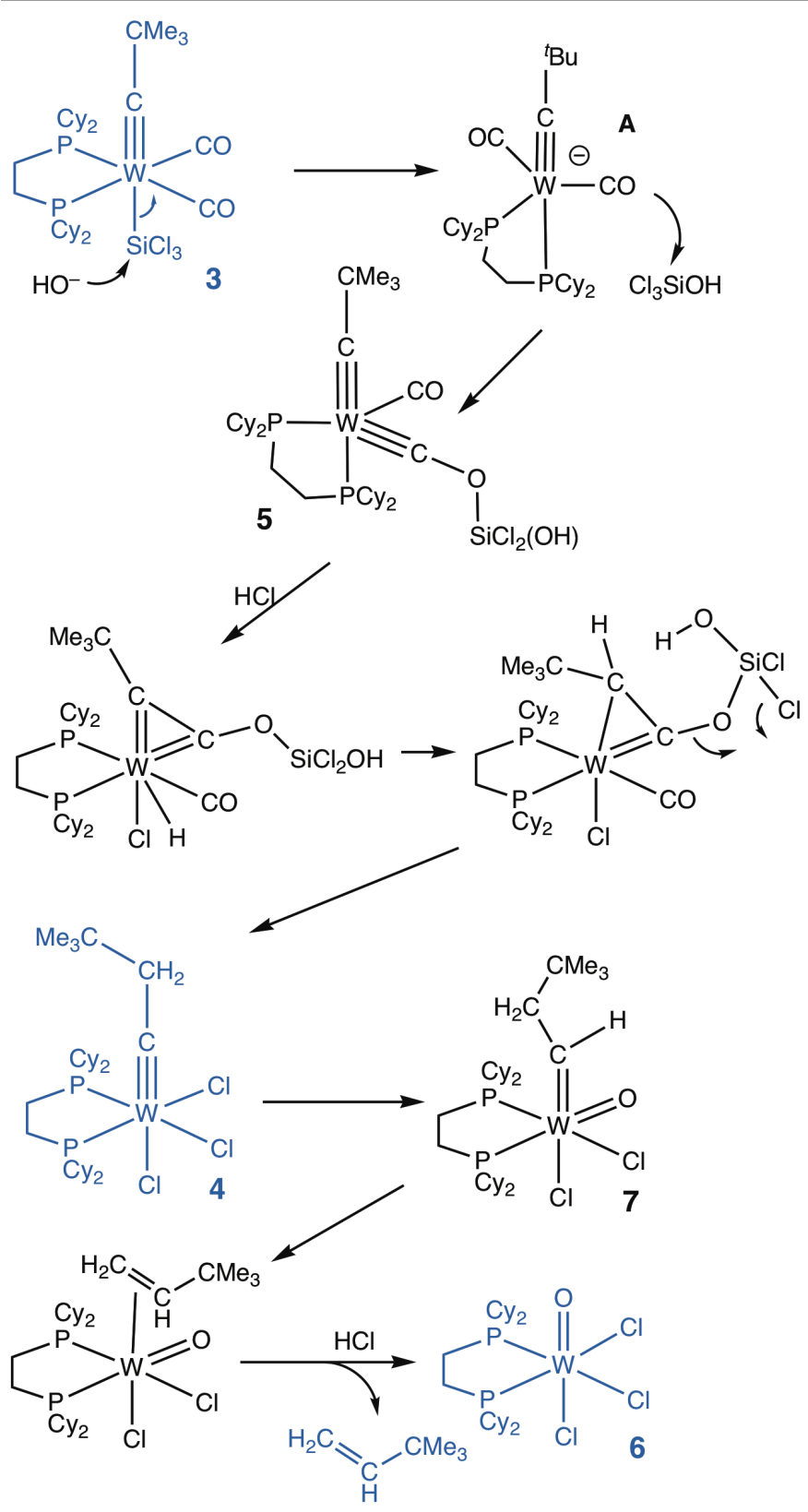

Scheme 2. Mechanistic Conjecture on the Reductive Coupling of Carbonyl and Alkylidyne Ligands and Subsequent Hydrolysis (neo-hexane and crystallographically characterised compounds shown in Blue).

\section{Conflict of interest}

The authors declare no conflicts of interest.

\section{Acknowledgements}

We gratefully acknowledge the Australian Research Council (DP170102695 and DP130102598) for funding.

\section{Notes and references}

$\dagger$ Throughout, we arbitrarily employ the $[C R]^{3-}$ formalism for oxidation state/d-configuration assignment. For discussions of carbyne coupling 25 however, the neutral $[C R]$ formalism is used. 
1 (a) J. A. Labinger, J. Organomet. Chem., 2017, 847, 4 - 12. (b) X. Zhang, Green. Chem., 2016, 18, 5086-5117. (c) S. S. Ail and S. Dasappa, Renew. Sust. Energ. Rev., 2016, 58, 267 - 286.

2 E. L. Muetterties and J. Stein, Chem. Rev., 1979, 79, 479-490.

3 (a) M. M. Deegan and J. C. Peters, J. Am. Chem. Soc., 2017, 139, 2561 - 2564. (b) Y. Lee and J. C. Peters, J. Am. Chem. Soc., 2011, 133, 4438 - 4446. (c) D. L. M. Suess and J. C. Peters, J. Am. Chem. Soc., 2013, 135, $12580-12583$.

4 F. R. Krei $\beta$ I, A. Frank, U. Schubert, T. L. Lindner and G. Huttner, Angew. Chem., Int. Ed. Engl. 1976, 15, $632-633$.

5 A. Mayr and C. M. Bastos, Prog. Inorg. Chem., 1992, 40, 1-98.

6 (a) J. A. Buss and T. Agapie, J. Am. Chem. Soc., 2016, 138, 16466-16477. (b) J. A. Buss and T. Agapie, Nature, 2016, 529, $72-75$.

7 A. F. Hill, J. S. Ward and Y. Xiong, Organometallics, 2015, 34, 5057-5064.

8 A. F. Hill and R. Y. Kong, Chem. Commun., 2017, 53, 2032 2035.

9 (a) S. K. Ignatov, A. Y. Khalimon, N. H. Rees, A. G. Razuvaev, P. Mountford and G. I. Nikonov, Inorg. Chem. 2009, 48, 96059622. (b) B. Adrjan and T. Szymanska-Buzar, J. Organomet. Chem. 2008, 693, 2163-2170. (c) S. H. A. Petri, B. Neumann, H.-G. Stammler and P. Jutzi, J. Organomet. Chem., 1998, 553, 317-329. (d) H. Piana and U. Schubert, J. Organomet. Chem., 1991, 411, 303-323. (e) A. M. Cardoso, R. J. H. Clark and S. Moorhouse, J. Organomet. Chem., 1980, 186, 241-245. (f) W. Malisch, Chem. Ber., 1974, 107, 3835-3849. (g) W. Malisch and M. Kuhn, Chem. Ber., 1974, 107, 283-2851. (h) W. Malisch and M. Kuhn, Chem. Ber., 1974, 107, 979-995. (i) W. Malisch, H. Schmidbaur and M. Kuhn, Angew. Chem., Int. Ed. Engl., 1972, 11, 516-517.

10 (a) J. M. Higgins, A. L. Schmitt, I. A. Guzei and S. Jin, J. Am. Chem. Soc., 2008, 130, 16086-16094. (b) A.-M. Lebuis, D. Christendat, D. F. R. Gilson and I. S. Butler Acta Crystallogr., Sect. C: Cryst. Struct. Commun., 1997, 53, 1206-1208 (c) X. Tao, M. Feng, Y.-Y. Zhang, Y.-Q. Li, N. Wang and Y.-Z. She, Chin. J. Struct. Chem. 2009, 28, 287. (d) L. Vancea, M. J. Bennett, C. E. Jones, R. A. Smith and W. A. G. Graham, Inorg. Chem., 1977, 16, 897-902.

11 (a) R. R. Schrock, Chem. Rev. 2002, 29, 227-256. (b) H.-S. Kim and R. J. Angelici, Adv. Oganomet. Chem., 1987, 27, 51-111. (c) A. Mayr and H. Hoffmeister, Adv. Organomet. Chem., 1991, 32, 227-324. (d) L. M. Caldwell, Adv. Organomet. Chem., 2008, 56, 1-94.

12 R. R. Schrock, D. N. Clark, J. Sancho, J. H. Wengrovius, S. M. Rocklage and S. F. Pedersen, Organometallics, 1982, 1, 16451651.

13 A. Mayr and G. A. McDermott, J. Am. Chem. Soc., 1986, 108, 548-549.

14 B. Haberlag, M. Freytag, C. G. Daniliuc, P. G. Jones and M. Tamm, Angew.Chem., Int.Ed., 2012, 51, 13019-13022

15 A. F. Hill and R. Y. Kong, Chem. Commun., 2017, 53, 759-762.

16 A. Fürstner, Angew. Chem., Int. Ed., 2013, 52, 2794-2819.

17 (a) J. Wengrovius, R. R. Schrock, M. R. Churchill, J. R. Missert and W. J. Youngs, J. Am. Chem. Soc., 1980, 102, 4515-4516. (b) S. M. Rocklage, R. R. Schrock, M. R. Churchill and H. J. Wasserman, Organometallics 1982, 1, 1332-1338.

18 J. H. Freudenberger and R. R. Schrock, Organometallics, 1985 , 5, 1937-1944.

19 W. A. Herrmann and J. Plank, Angew. Chem., Int. Ed. Engl., 1978, 17, 525-526.

20 (a) F. R. KreißI, W. J. Sieber, M. Wolfgruber and J. Riede, Angew. Chem. Int. Ed. Engl. 1984, 23, 640.

21 S. J. Holmes, R. R. Schrock, M. R. Churchill and H. J. Wasserman, Organometallics, 1984, 3, 476-484.

22 (a) R. N. Vrtis, C. P. Rao, S. Warner and S. J. Lippard, J. Am. Chem. Soc., 1988, 110, 2669-2670. (b) R. N. Vrtis, S. Liu, C. P. Rao, S. G. Bott and S. J. Lippard, Organometallics, 1991, 10, 275-285. (c) J. D. Protasiewicz and S. J. Lippard, J. Am. Chem.
Soc., 1991, 113, 6564-6570 (d) J. D. Protasiewicz, A. Masschelein and S. J. Lippard, J. Am. Chem. Soc., 1993, 115, 808-810. (e) J. D. Protasiewicz, B. S. Bronk, A. Masschelein and S. J. Lippard, Organometallics, 1994, 13, 1300-1311.

23 P. A. Bianconi, R. N.Vrtis, C. P. Rao, I. D. Williams, M. P. Engeler and S. J. Lippard, Organometallics, 1987, 6, 1968-1977.

24 (a) J. Chatt, A. J. L. Pombeiro and R. L. Richards, J. Chem. Soc., Dalton Trans., 1980, 492-498. (b) A. C. Filippou, W. Grünleitner, C. Völkl and P. Kiprof, Angew. Chem. Int. Ed. Engl. 1991, 30, 1167-1169. (c) A. C. Filippou, P. Hofmann, P. Kiprof, H. R. Schmidt and C. Wagner, J. Organomet. Chem., 1993, 459, 233-247.

25 (a) C. N. Wilker, R. Hoffmann and O. Eisenstein, J. Am. Chem. Soc., 1982, 104, 632-634. (b) C. N. Wilker, R. Hoffmann and O. Eisenstein, Nouv. J. Chim. 1983, 7, 535-544. (b) D. C. Brower, J. L. Templeton and D. M. P. Mingos, J. Am. Chem. Soc., 1987, 109, 5203-5208.

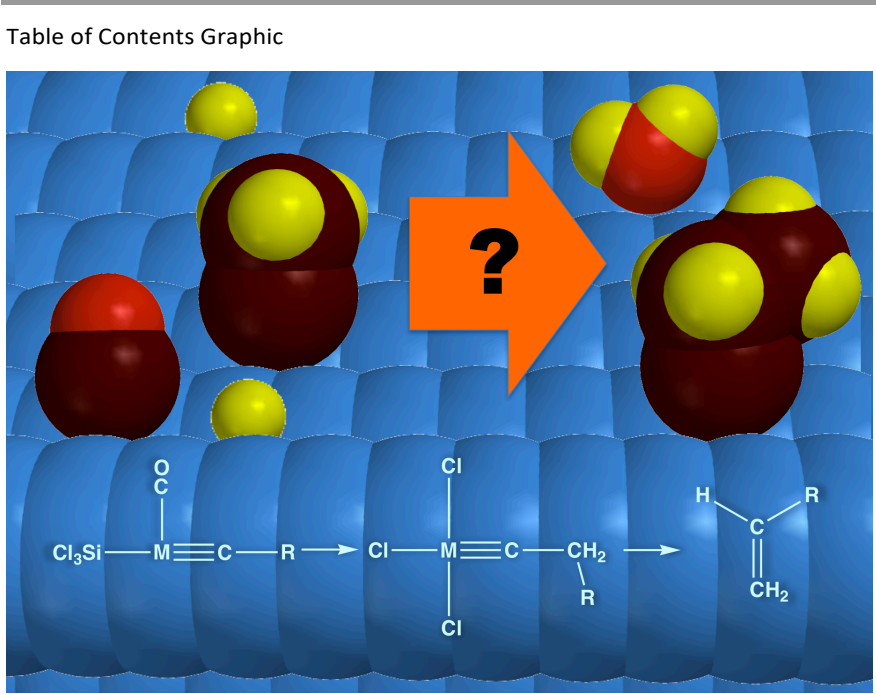

